\section{How should neonatal clinicians act in the presence of moral distress?}

\author{
Trisha M Prentice $0^{1,2,3}$ Lynn Gillam, $^{2,4}$ Annie Janvier, ${ }^{5}$ \\ Peter G Davis (1) ${ }^{6,7}$
}

Hannah was born at $23+1$ weeks. At 2 weeks of age, Hannah developed severe necrotising enterocolitis requiring extensive resection of her small bowel. She remains ventilated and dependent on inotropes. Additionally, Hannah is known to have bilateral grade IV intraventricular haemorrhages. The doctors and nurses caring for her believe that it is very unlikely she will survive and if she does, major disability is almost inevitable. The treating team has communicated its concerns to her parents several times over the past 48 hours and has suggested discontinuing lifesustaining interventions. Her parents understand the recommendation but have requested that 'everything be done to save their baby's life'. This leads to considerable distress among many team members who believe ongoing life-sustaining treatment is no longer in Hannah's interests.

Moral distress is increasingly recognised as an important issue affecting the wellbeing of clinicians. It is the anguish that occurs when clinicians are prevented from acting in accordance with their moral judgements. ${ }^{1}$ Most commonly, moral distress reflects the belief that a child is receiving disproportionate care ('doing too much') that is not in his or her interests, ${ }^{2}$ as in the case of Hannah. Historically, moral distress has often been framed as an institutional failing ${ }^{3}$ where medical hierarchy enforces nurses and medical residents to provided futile care against their better judgement and without a viable pathway for their concerns to be heard. The term 'moral distress' has therefore become

\footnotetext{
${ }^{1}$ Neonatal Medicine, The Royal Children's Hospital, Melbourne, Victoria, Australia

${ }^{2}$ Melbourne School of Population and Global Health, University of Melbourne, Melbourne, Victoria, Australia ${ }^{3}$ Neonatal Research, Murdoch Children's Research Institute, Melbourne, Victoria, Australia ${ }^{4}$ Children's Bioethics Centre, The Royal Children's Hospital, Melbourne, Victoria, Australia ${ }^{5}$ Pediatrics and Clinical Ethics, University of Montreal, Montreal, Québec, Canada

${ }^{6}$ Department of Obstetrics and Gynaecology, University of Melbourne, Melbourne, Victoria, Australia ${ }^{7}$ Newborn Research, The Royal Women's Hospital, Parkville, Victoria, Australia
}

Correspondence to Dr Trisha M Prentice, Neonatal Medicine, The Royal Children's Hospital Melbourne, Parkville VIC 3052, Australia;

trisha.prentice@rch.org.au something of a buzzword, used to demand action to overcome these perceived institutional failings, to empower distressed clinicians and thereby to eliminate moral distress within the institution. Within paediatric acute care settings, literature on moral distress generally implies that, to optimally address moral distress, the management plan for a patient needs to change, often to palliative care. However, that may be too narrow a view. How clinicians should act in the presence of and in response to moral distress merits further consideration. We shall argue here that moral distress does not necessarily reflect an institutional failing, and a greater acceptance of moral distress may be required within the context of shared decision-making.

The anguish associated with moral distress is legitimate and real. It originates from a sincere concern that the current management plan is not in the patient's interests. Yet, in the literature on moral distress, the underlying judgement that a patient is being harmed is rarely questioned; in fact, it is usually assumed to be correct. If that were clearly the case, action to protect the interests of the patient would be warranted and commendable. However, within acute care settings, it is often very difficult to define the point at which a patient is objectively being harmed or where the burdens of treatment demonstrably outweigh the benefits. Indeed, developments in medical technology have brought us to a place of medical and moral uncertainty.

In paediatrics, we recognise parents as proxy decision-makers for their child as long as their decisions do not result in harm to the child. ${ }^{4}$ Yet knowing where to draw the line between an approach that is unequivocally harming a child and one that lies within the zone of parental discretion is extremely difficult. Within this zone, parents have a legitimate say in the care of their child even if that care is perhaps not what we, as clinicians, believe is ideal. ${ }^{5}$ Sometimes, all clinicians in a team agree about a treatment plan (generally palliative care) when parents want to continue life-sustaining interventions. However, clinicians may have different moral positions on whether treatment can be limited without parental agreement, or how long it is acceptable to continue these interventions while waiting to achieve parental agreement through ongoing discussions. In other instances, individual members of the team may differ in their judgement about whether a management plan has reached the point of harm, due to their own personal beliefs and values. Whose judgement or voice should we uphold? Since the clinicians are not unified in their views that treatment constitutes harm, it is reasonable to consider that treatment remains within the zone of parental discretion and to respect the parental wishes. In both sets of circumstances, there will be some members of the team who will have to provide ongoing care in line with the family's wishes despite personally considering that treatment harmful to the patient.

The constraint preventing distressed clinicians from acting according to their own value under such circumstances does not necessarily reflect an institutional failing or abuse of power within the medical hierarchy. Rather, it may reflect the healthcare profession's current commitment to shared decision-making and the legitimate role of parents as proxy decision-makers for their child. The response of a clinician to moral distress should reflect the nature of the constraint; that is, greater action or change should be expected where the constraint reflects an abuse of power or institutional failing, compared with cases in which the constraint (eg, parental wishes for ongoing life-sustaining treatments) derives from moral considerations which are legitimately open to interpretation.

Currently, interventions to address moral distress often encourage empowerment of clinicians to advocate for desired changes in the treatment plan. ${ }^{67}$ This can have negative consequences. If a clinician persists in fighting for a change to a palliative pathway where life-sustaining treatment remains within the zone of parental discretion, this may simply further frustrate and heighten that clinician's distress; their desired plan is unlikely to be implemented if other clinicians within the treating team continue to respect the parents' legitimate wishes for ongoing lifesustaining interventions. There is also a risk that morally distressed clinicians may impose their views on others, when there is room for legitimate difference of moral views, thus potentially causing moral distress to others. This may be particularly problematic if the views are imposed on the family entrusted to the clinician's 
care. Trust and the therapeutic relationship between clinician and family may be compromised.

A more ethically appropriate response to moral distress by the clinician should involve reflective practice, that is, selfreflection about the source of moral distress and consideration of whether further information or further ethical thinking is required before a position is taken. Reflective questions may include ${ }^{8}$ the following: Why do I feel morally distressed? Do others feel likewise, and why? Am I able to continue caring for the patient or is my moral distress harming the patient? What are the available, reasonable options in this case? Resolving personal moral distress should not be the primary aim. Rather, the central focus should remain on the patient.

Although institutional structures may not be directly responsible for the presence of moral distress-that is, the institution is not the 'constrainer' preventing the clinician's action-the institution has an obligation to seek to reduce the foreseeable effects of moral distress on clinicians. Institutions should provide an ethical climate where all concerned voices are heard and considered and management plans are reviewed. Both the distressed clinician and others within the institution should communicate professionally and with respect. The presence of moral distress should prompt constructive conversations and consideration about what is in the patient's interests and whether the current treatment plan remains within the zone of parental discretion. However, the presence of moral distress should not necessarily dictate a change in management plan. It is not always possible to fully resolve everyone's moral distress due to differing views about what constitutes the patient's interests. Constructive discussions of this nature, even if distressing, may be of significant benefit in clarifying the goals of care for a patient and progress medical management in an ethically sensitive manner. Where a decision legitimately remains within the zone of parental discretion, clinicians who believe the child is being harmed must be supported in their ongoing provision of care, acknowledging the potential costs and burdens to the clinician. Where possible, particularly affected individuals may need reduced exposure to patients likely to cause distress and be supported to access external counselling services. Ethics committees may assist in the process of reflective practice: clarifying the ethical question and disentangling moral distress from other forms of distress, including that which arises from tragic circumstances. However, where differences of opinions cannot be resolved, clinicians may need to focus on finding meaning in things that they can achieve, whether it be reducing pain and suffering through adequate analgesia or sedation, or supporting the interactions between parent and child. Attention to personal self-care is essential under such circumstances.

Moral distress is not necessarily an institutional failing. Rather, it may arise from personal values and professional obligations to respect parents as decision-makers for their child. Sometimes, action may be limited to finding meaning in our duty to care for patients and families, and to support our colleagues, despite differences of opinions. Sometimes, it may even mean accepting some degree of moral distress in order to uphold one's professional duty to ongoing care provision and the practice of shared decision-making.

Contributors All authors have made substantial contributions to the conception of this article, revising it critically and approving the final version.
Funding The authors have not declared a specific grant for this research from any funding agency in the public, commercial or not-for-profit sectors.

Competing interests None declared.

Patient consent for publication Not required.

Provenance and peer review Commissioned; externally peer reviewed.

(C) Author(s) (or their employer(s)) 2020. No commercial re-use. See rights and permissions. Published by BMJ.

\section{Check for updates}

To cite Prentice TM, Gillam L, Janvier A, et al. Arch Dis Child Fetal Neonatal Ed 2020;105:F348-F349.

Received 5 November 2019

Accepted 8 January 2020

Published Online First 22 January 2020

Arch Dis Child Fetal Neonatal Ed 2020;105:F348F349. doi:10.1136/fetalneonatal-2019-317895

\section{ORCID iDs}

Trisha M Prentice http://orcid.org/0000-0003-4271 7950

Peter G Davis http://orcid.org/0000-0001-6742-7314

\section{REFERENCES}

1 Jameton A. Nursing practice: the ethical issues/ Andrew Jameton; with a foreword by Ingeborg $G$. Mauksch. Englewood Cliffs, New Jersey: Prentice-Hall, 1984: 6. 282-95.

2 Prentice T, Janvier A, Gillam L, et al. Moral distress within neonatal and paediatric intensive care units: a systematic review. Arch Dis Child 2016;101:701-8.

3 Epstein EG, Hurst AR. Looking at the positive side of moral distress: why it's a problem. J Clin Ethics 2017:28:37-41.

4 Diekema DS. Parental refusals of medical treatment: the harm principle as threshold for state intervention. Theor Med Bioeth 2004;25:243-64.

5 Gillam L. The zone of parental discretion: an ethical tool for dealing with disagreement between parents and doctors about medical treatment for a child. Clin Ethics 2016:11:1-8.

6 Abbasi S, Ghafari S, Shahriari M, et al. Effect of moral empowerment program on moral distress in intensive care unit nurses. Nurs Ethics 2019;26:1494-504.

7 Aliso Viejo C. The 4A's to rise above moral distress, 2004.

8 Prentice TM, Gillam L, Davis PG, et al. The use and misuse of moral distress in neonatology. Semin Fetal Neonatal Med 2018;23:39-43. 